\title{
Effects of an artificial diet on growth of patients with cystic fibrosis
}

\author{
J. G. YASSA, R. PROSSER, AND J. A. DODGE \\ From Department of Child Health, University Hospital of Wales, Cardiff and Department of Paediatrics, \\ Royal Gwent Hospital, Newport
}

SUMmARY The effects of an artificial diet on growth were examined in a controlled trial on 43 patients with cystic fibrosis. 28 patients received the diet for 12 months. Comparison was made between their growth before, during, and after dietary treatment. Growth changes were also assessed in 15 other patients who received a conventional diet. Artificial dietary treatment led to some improvement in height, weight, subscapular skinfold thickness, and a disproportionate advance of bone age for the group as a whole. Only $10(36 \%)$ patients had a 'clinically' significant improvement in height, weight, or both-i.e. more than 0.5 standard deviation score. Greatest improvements were in young and mildly affected patients. It is proposed that the future use of such an unpleasant and expensive diet should be restricted to a few selected cases, rather than given as routine treatment.

The adverse effects of cystic fibrosis (CF) on growth and nutrition have long been recognised (Passini, 1919; Clarke and Hadfield, 1924; Harper, 1930; Sproul and Huang, 1964), and despite improved treatment, recent studies have shown that both the heights and weights of patients are markedly skewed towards the lower centile bands (Berry et al., 1975; Lober, 1975). As $70 \%$ of patients with CF can now be expected to live to age 17 (Robinson and Norman, 1975), and many survive to adulthood, the ultimate achievement of normal stature and weight has become important. Recent reports have claimed that growth may be improved by an artificial diet (Allan et al., 1973; Berry et al., 1975). We have examined the effects of this diet on growth in a controlled trial.

\section{Patients and methods}

Forty-three patients with CF were assessed for 24 to 30 months (Fig. 1). After an initial period of 6 months on conventional treatment, the artificial diet was offered to patients irrespective of the severity of their disease. Group 1 (28 patients) completed a period of 12 months' dietary treatment and progress was followed for 12 months after the artificial diet had been discontinued. Each patient acted as his or her own control. There were 16 boys and 12 girls in group 1 , mean age 7.99 years, mean clinical score $72 \cdot 86 \%$ according to the method of Doershuk et al. (1964) (Table 1).

Received 12 April 1977

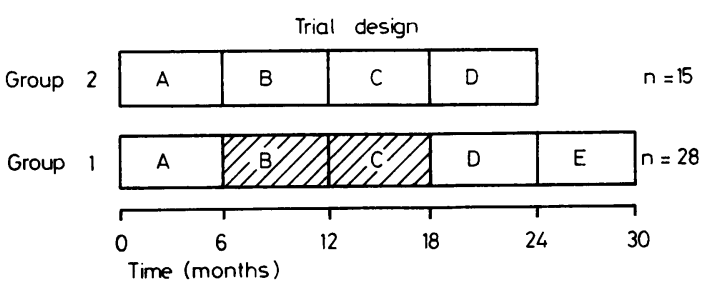

Fig. 143 patients with $C F$ were assessed for a maximum period of 36 months. All patients received conventional diet for the first 6 months. 28 patients (group 1) received the artificial diet for 12 months (shaded area), 15 (group 2) continued on conventional diet for 24 months. Patients were assessed at 6-monthly periods, i.e. $A, B, C, D, E$.

Table 1 Clinical assessment

\begin{tabular}{|c|c|c|c|}
\hline \multirow[t]{2}{*}{ Group } & \multirow{2}{*}{$\begin{array}{l}\text { No. of } \\
\text { patients }\end{array}$} & \multirow{2}{*}{$\frac{\text { Age }(\text { years })}{\text { Mean }(\text { range })}$} & \multirow{2}{*}{$\frac{{ }^{*} \text { Clinical score }(\%)}{\text { Mean (range) }}$} \\
\hline & & & \\
\hline $\begin{array}{l}1 \\
2\end{array}$ & $\begin{array}{l}28 \\
15\end{array}$ & $\begin{array}{l}7.99(3 \cdot 23-16 \cdot 02) \\
5 \cdot 74(2 \cdot 26-12 \cdot 71)\end{array}$ & $\begin{array}{l}72 \cdot 86(40-92) \\
74 \cdot 87(53-97)\end{array}$ \\
\hline
\end{tabular}

*Clinical score according to Shwachman and Kulczycki (1958) and modified by Doershuk et al. (1964).

Group 2 (15 patients) continued on conventional treatment-i.e. normal low fat diet, pancreatic supplements, physiotherapy, and antibiotics as required. Many in this group had refused to take part in the dietary trial. Their ages and clinical scores were comparable with those in group 1 (Table 1). 
Longitudinal growth measurements were analysed at 6-monthly intervals. In group 1, comparison was made between changes in growth, before (period A, 6 months), during (periods B and C, 12 months), and after (periods $\mathrm{D}$ and $\mathrm{E}, 12$ months) treatment with artificial diet (Fig. 1). A similar comparison was made in patients of group 2 between the corresponding periods-i.e. period A (6 months), B and C (12 months), and D (6 months) (Fig. 1). Patients in group 2 were available for assessment during 24 months only. Comparison was also made between the patients in groups 1 and 2 . Some patients were admitted to the study in April and others in October, in an attempt to minimise the effect of seasonal variation on growth. The predietary observation period was limited to 6 months for 2 reasons: firstly, assessment in 26 patients during a 12-month period showed no significant difference between the change in growth in the first and the second 6 months; secondly, many parents were impressed by the early reports describing the success of the treatment given by Allan et al. (1973) and were anxious that their children should start treatment as soon as possible.

Dietary treatment. The artificial diet used in this study was that proposed by Allan et al. (1973). It consisted of beef serum hydrolysate (Albumaid complete), a glucose polymer (Gastro-Caloreen), medium chain triglyceride oil (MCT), a mineral supplement (Metabolic Mineral Mixture), vitamin preparations providing a number of fat and water soluble vitamins (Ketovite), and margarine or eggs.

The diet was prescribed in amounts sufficient to provide all the daily requirement of protein and calories. Its final composition was on average: 6 to $10 \%$ of total calories from protein, 75 to $85 \%$ from carbohydrates, and 10 to $15 \%$ from fat (Allan et al., 1973). Between 0.6 and 1 litre water was added to the recommended amounts of Albumaid, GastroCaloreen, and mineral supplements. The mixture was flavoured and divided into four or five portions which were taken during the day.
The other components of the diet were taken separately. Patients were allowed to eat normal low fat food if they wished. Most patients ate some extra food but there was noticeable reduction in their appetites. Pancreatic supplements were given in proportion to the food eaten.

Measurements. Measurements of height, weight, head circumference, subscapular and triceps skinfold thickness were made at each visit to the clinic every 4-6 weeks. Anthropometric measurements were converted to standard deviation (SD) scores from norms for age and sex. SD scores were calculated using the formula SD score $=\frac{X-\bar{X} \text {. }}{S_{X}}$ Where $X$ is the patient's measurement, $\bar{X}$ the mean measurement of normal children of the same sex and age, and $S_{X}$ the SD at a particular age. Normal values were based on British children (Tanner, 1973; Tanner and Whitehouse, 1975; Tanner et al., 1966, 1975). Longitudinal growth measurements were made in all 43 patients. Changes in the SD scores were analysed every 6 months.

Bone age was assessed by TW2 method (Tanner et al., 1975). Assessments were made once every 6 months and bone age was converted to the SD score as described. Height SD scores were also derived using the child's bone age instead of his chronological age, and these were expressed as adjusted SD scores. Changes in adjusted height scores were analysed in an attempt to assess whether changes in bone age were associated with equivalent changes in height.

\section{Results}

Significantly negative SD scores of height, weight, head circumference, skinfold thickness, and bone age were observed in the $\mathbf{4 3}$ patients at the beginning of the study. The mean values were approximately 1 SD below the mean for normal children of the same age and sex. Head growth and triceps skinfold thickness were less depressed than other parameters (Table 2).

Table 2 Assessment of anthropometric parameters

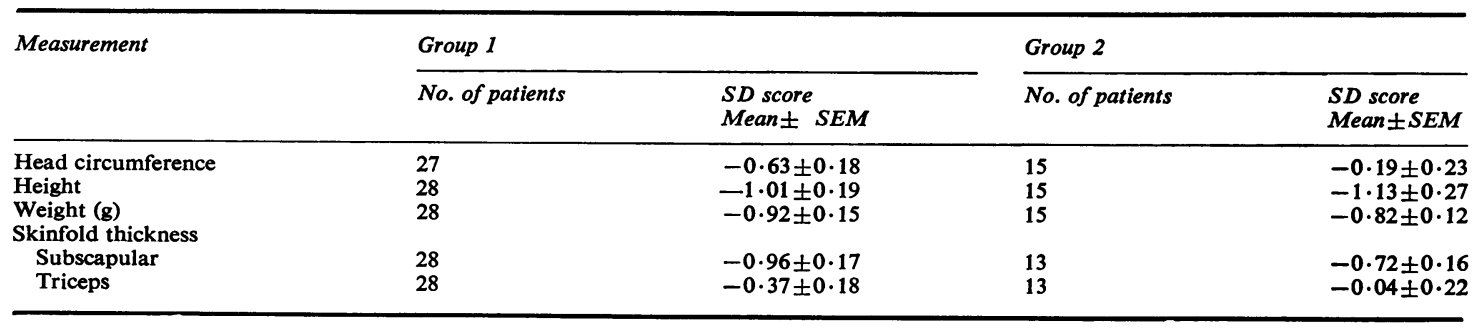




\section{Group 1.}

\section{Anthropometric measurements}

Changes before dietary treatment (period A). Mean changes in SD scores of height, weight, subscapular and triceps skinfold thickness in period $\mathrm{A}$ were not statistically significant. There was a small positive change in the mean score of head circumference (Table 3).

Changes during dietary treatment (periods $B$ and $C$ ). There was a significant increase in weight, height, and subscapular skinfold thickness (Figs 2, 3, and 4; Table 3), but there were no significant changes in the SD scores of head circumference and triceps skinfold thickness. The improvement in height, weight, and subscapular skinfold thickness was most noticeable in period B (the first 6 months of dietary treatment) (Fig. 5). Younger patients showed

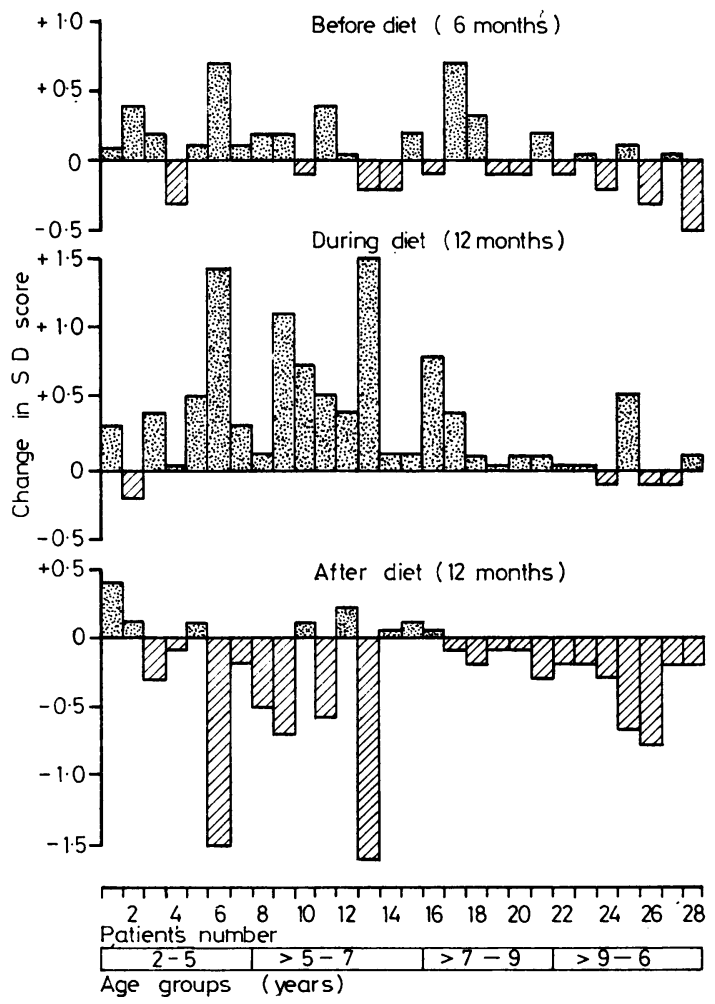

Fig. 2 Changes in weight in 28 patients expressed as changes in SD scores, before, during, and after treatment with artificial diet. Each column represents the change in one patient; positive values , negative values $\oslash$. Patients are arranged according to age, increasing from left to right. the greatest change. Height gain was of a lesser degree than weight gain. If one may empirically consider a change of $+0.5 \mathrm{SD}$ score as indicative of a clinically significant improvement, then $10(35.7 \%)$ patients improved in weight, height, or both, 8 (28.6\%) improved in weight, $6(21.4 \%)$ improved in height, and only $4(14.3 \%)$ improved in both weight and height.

Changes after the diet was stopped (period D and E). Many patients lost weight while others continued to gain at a slower rate. Height increase also continued at a slower rate than that observed during the dietary period. There were significantly negative changes in the SD scores of height, weight, head circumference, subscapular and triceps skinfold thickness (Figs 2, 3, and 4; Table 3).

\section{Bone age}

The mean SD score at the end of the dietary treatment was significantly less retarded than the mean score 6 months before the artificial diet had been started (Table 4). This advancement in bone age continued after the diet had been stopped.

When the patients' heights were adjusted for bone age, negative changes were observed in the adjusted height SD scores during the dietary period and the

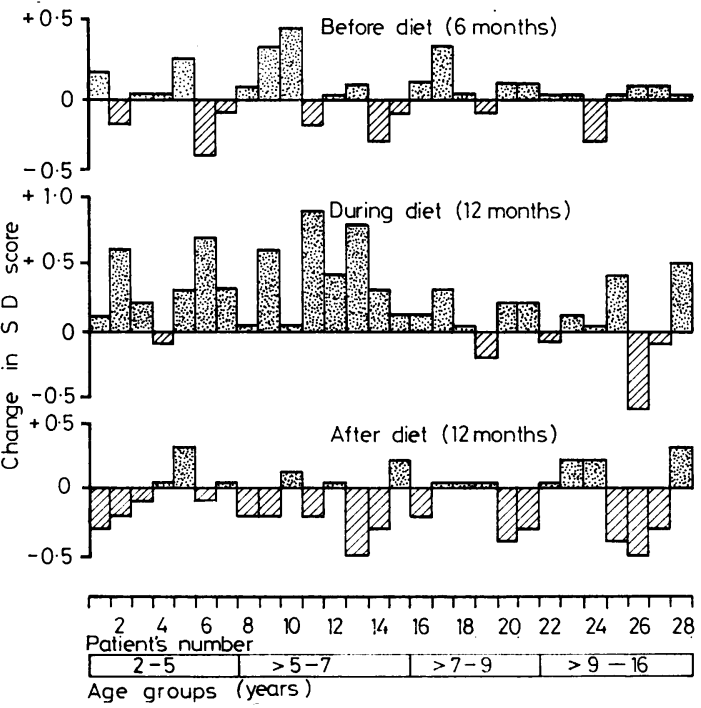

Fig. 3 Changes in height in 28 patients expressed as changes in SD scores, before, during, and after treatment with artificial diet. Each column represents the change in one patient; positive values negative values . Patients are arranged according to age, increasing from left to right. 
12 months that followed. This indicates that advancement of bone age was not accompanied by an appropriate increase in height (Table 4).

\section{Group 2.}

Anthropometric measurements

Mean changes in SD scores of height, weight, head circumference, subscapular and triceps skinfold

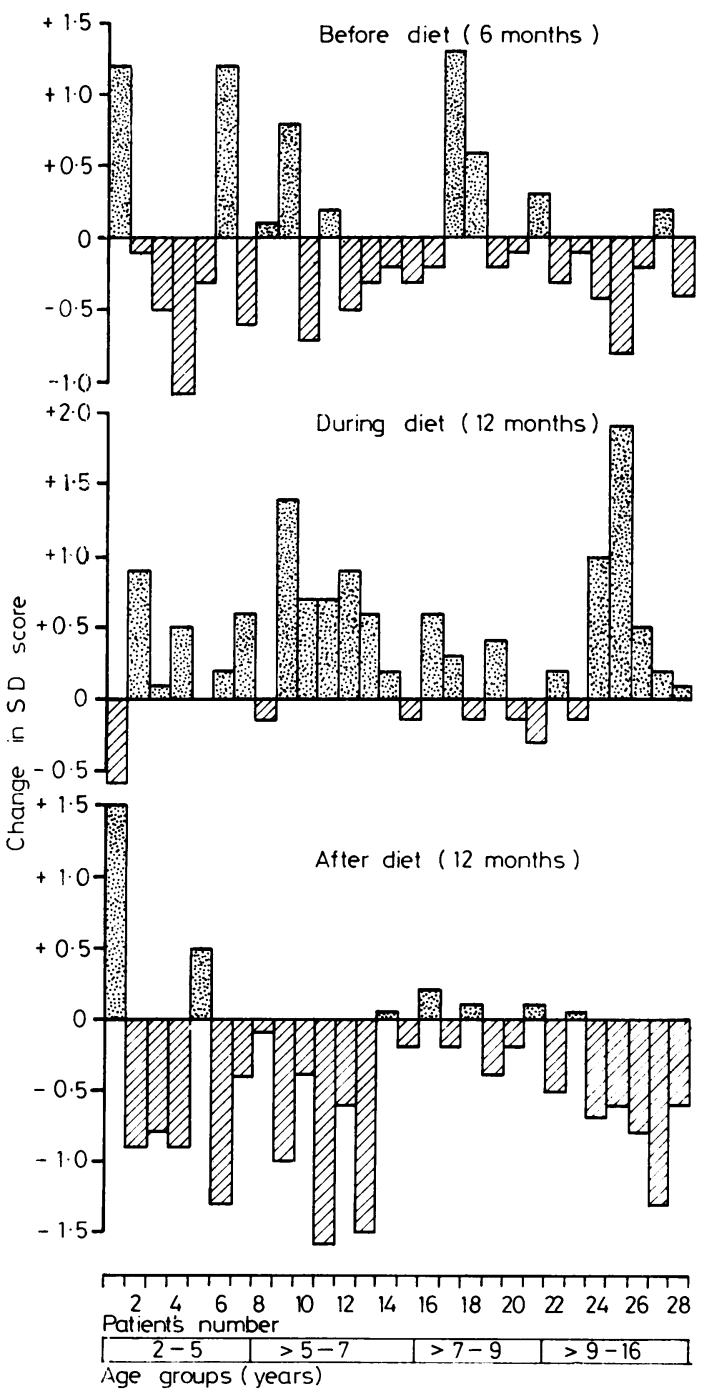

Fig. 4 Changes in subscapular skinfold thickness in 28 patients expressed as changes in $S D$ scores, before, during, and after treatment with artificial diet. Each column represents the change in one patient; positive values $\mathrm{S}$, negative values $D$. Patients are arranged according to age, increasing from left to right. thickness were not statistically significant during any of the 3 periods of assessment; period A (6 months), B and C (12 months), and D (6 months) (Table 3). The mean changes in scores did not differ from changes observed in patients of group 1 during the 6-month period before the diet was begun.

\section{Bone age}

The mean SD score at the beginning of the study was slightly better than the mean scores 12 or 24 months later (Table 5). When height was adjusted for bone age, the mean adjusted height scores were similar at the beginning of the study and 12 or 24 months later, indicating that the changes in bone age were paralleled by changes in height.

\section{Discussion}

The artificial diet given over 12 months led to a significant increase in height, weight, subscapular skinfold thickness, and bone age. This increase occurred mainly during the first 6 months of dietary treatment, which could reflect either a stabilisation of growth after a period of rapid gain or diminishing enthusiasm of the patients to take all their diet. The diet was unpleasant and continuous persuasion and encouragement were needed with some patients. To the best of our knowledge, most of the patients took all the recommended dietary treatment. Younger patients showed more significant improvement than older ones and, unfortunately, very small patients showed the least improvement. In those who improved, the gain in weight was partly a result of increase in lean body mass as shown by increase in height, and partly a result of fat deposition as shown by increase in the subscapular skinfold thickness. Although there was no similar increase in the triceps skinfold thickness during the dietary period, the absence of a decrease in this parameter may be significant since there is progressive decrease in triceps skinfold thickness with advancing age in patients with CF (J. G. Yassa, personal observation). The absence of change in head circumference was expected as all our patients were older than 3 years. There was a slight increase in the head circumference scores before the diet was started for which no explanation could be found.

When the diet was discontinued many patients lost weight and others continued to gain but at a slower rate. This was associated with decrease in the standard score of both subscapular and triceps skinfold thickness. Weight loss in some patients was very rapid which led us to suspect the possibility of fluid rentention during the dietary treatment. Total body water was studied in a few patients but there was no convincing evidence of fluid retention. 
Height gain became much slower after the diet was discontinued and at the same time there was a significantly negative change in the standard scores of head circumference. It is difficult to explain the changes in head growth after the discontinuation of the diet, but metabolic deficiencies produced by an artificial diet could not be excluded.
The artificial diet led to advancement in bone age, an effect which persisted even after the diet was stopped. The increase in height was of a lesser degree-i.e. bone age became relatively more advanced than height. Most patients with CF have a delayed bone age, consequently growth may continue for a longer period than in normal children.

Table 3 Change in anthropometric measurements

\begin{tabular}{|c|c|c|c|c|c|c|c|c|}
\hline \multirow[t]{3}{*}{ Measurements } & \multicolumn{4}{|c|}{ Patients who received artificial diet (group 1) } & \multicolumn{4}{|c|}{ Patients who received conventional diet (group 2) } \\
\hline & \multirow[b]{2}{*}{$n$} & \multicolumn{3}{|c|}{ Change in $S D$ scores } & \multirow[b]{2}{*}{$n$} & \multicolumn{3}{|c|}{ Change in $S D$ scores } \\
\hline & & $\begin{array}{l}\text { Period } \\
\boldsymbol{A}\end{array}$ & $\begin{array}{l}\text { Periods } \\
B \text { and } C\end{array}$ & $\begin{array}{l}\text { Periods } \\
D \text { and } E\end{array}$ & & $\begin{array}{l}\text { Period } \\
A\end{array}$ & $\begin{array}{l}\text { Periods } \\
B \text { and } C\end{array}$ & $\begin{array}{l}\text { Period } \\
D\end{array}$ \\
\hline Head & & $*$ & & $* *$ & & & & \\
\hline circumference & 27 & $+0.11 \pm 0.05$ & $\underset{* *}{+} \quad \pm 0.07$ & $-0.15 \pm 0.05$ & 15 & $-0.03 \pm 0.10$ & $-0.22 \pm 0.13$ & $0 \pm 0 \cdot 10$ \\
\hline Height & 23 & $+0.02 \pm 0.04$ & $\underset{* * *}{+0.21 \pm 0.06}$ & $\underset{* *}{-0.10 \pm 0.04}$ & 15 & $+0.05 \pm 0.05$ & $-0.08 \pm 0.08$ & $-0.09 \pm 0.05$ \\
\hline \multirow{3}{*}{$\begin{array}{l}\text { Weight } \\
\text { Subscapular skinfold } \\
\text { thickness } \\
\text { Tricepsskinfold } \\
\text { thickness }\end{array}$} & 28 & $+0.06 \pm 0.05$ & $\underset{* * *}{+0.32 \pm 0.08}$ & $-0.29 \pm 0.09$ & 15 & $+0 \cdot 11 \pm 0 \cdot 10$ & $+0.01 \pm 0.10$ & $-0.03 \pm 0.08$ \\
\hline & 28 & $-0.05 \pm 0.11$ & $+0 \cdot 38 \pm 0 \cdot 10$ & $-0.45 \pm 0.12$ & 13 & $-0.06 \pm 0.12$ & $+0.33 \pm 0.17$ & $-0.04 \pm 0.09$ \\
\hline & 28 & $+0.09 \pm 0.13$ & $-0.02 \pm 0.11$ & $-0 \cdot 30 \pm 0 \cdot 14$ & 13 & $+0 \cdot 22 \pm 0 \cdot 19$ & $+0.08 \pm 0.19$ & $+0.10 \pm 0.09$ \\
\hline
\end{tabular}

Mean \pm SEM.

$* P<0.05, * * P<0.01, * * * P<0.001$.
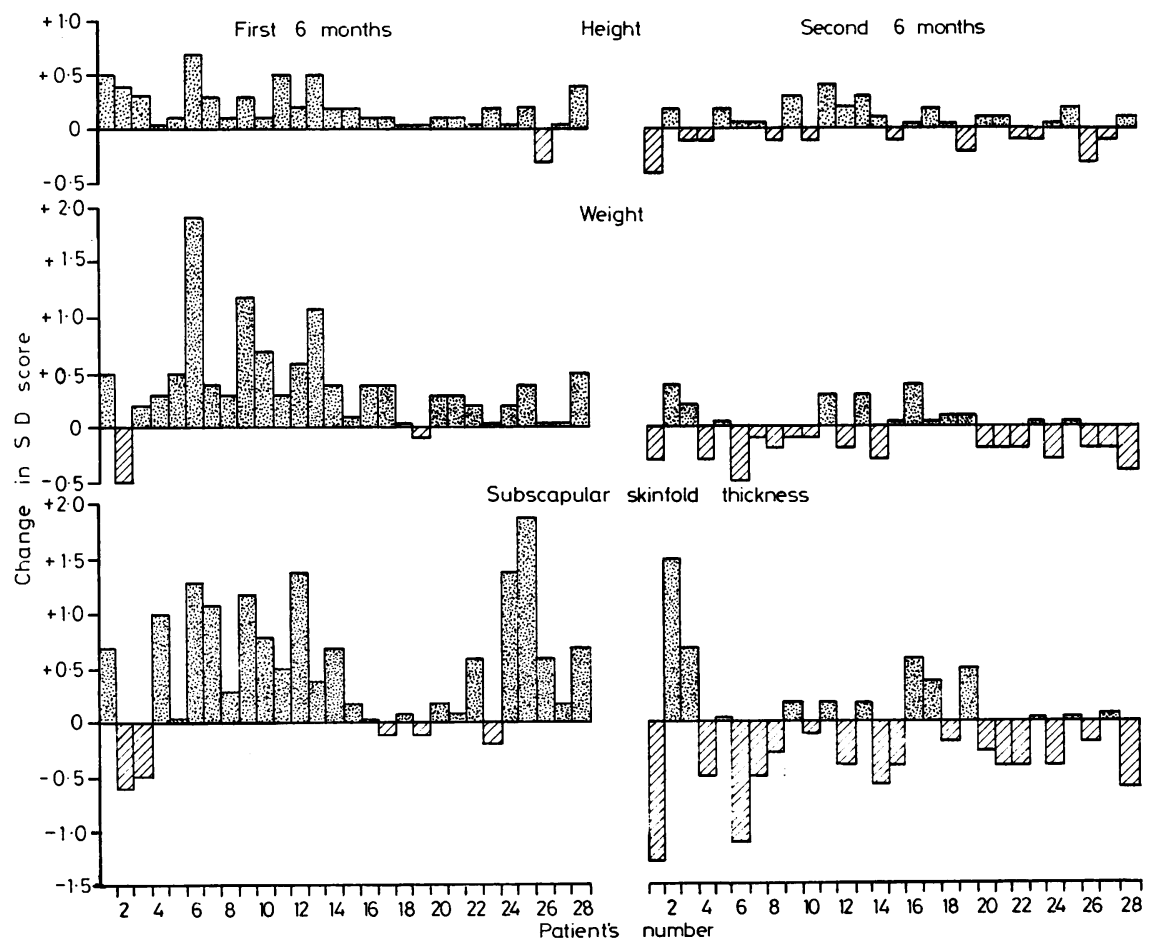

Fig. 5 Comparison between changes in the first and second 6 months during dietary treatment. Changes in height, weight, and subscapular skinfold thickness are given in 28 patients. Each column represents the change in one patient,

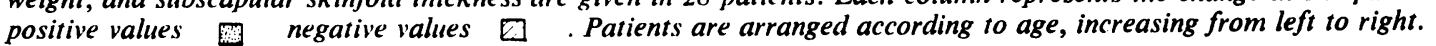


Table 4 Bone age and adjusted height in patients who received artificial diet

\begin{tabular}{|c|c|c|c|c|c|}
\hline Measurement & $\begin{array}{l}\text { Age (years) } \\
\text { mean (range) }\end{array}$ & No. of patients & Period $A$ & Periods $B$ and $C$ & Periods $D$ and $E$ \\
\hline & & & & & $* * * *$ \\
\hline Bone age & $6.55(3.99-8.96)$ & 12 & $-1 \cdot 24 \pm 0.55$ & - & $\underset{* * * *}{-0.16 \pm 0.33}$ \\
\hline Adjusted height & & & $+0.45 \pm 0.49$ & $\overline{* *}$ & $\frac{-1 \cdot 27 \pm 0.35}{* * *}$ \\
\hline Bone age & $6 \cdot 27(3 \cdot 99-8 \cdot 88)$ & 9 & $-1 \cdot 22 \pm 0.38$ & $-0.49 \pm 0.41$ & $-0.02 \pm 0.33$ \\
\hline Adjusted height & & & $+0.48 \pm 0.65$ & $-0.41 \pm 0.49$ & $-1 \cdot 18 \pm 0.46$ \\
\hline
\end{tabular}

Mean \pm SEM.

${ }_{* *} \mathrm{P}<0.02 ; * * * P<0.01 ; * * * * P<0.001$.

Table 5 Bone age and adjusted height in patients who received conventional diet

\begin{tabular}{|c|c|c|c|c|}
\hline Measurement (SD score) & No. of patients & Beginning of assessment & 12 months' assessment & 24 months' assessmen \\
\hline $\begin{array}{l}\text { Bone age } \\
\text { Adjusted height } \\
\text { Bone age } \\
\text { Adjusted height }\end{array}$ & $\begin{array}{r}12 \\
12 \\
7 \\
7\end{array}$ & $\begin{array}{l}-0.96 \pm 0.29 \\
+0.05 \pm 0.31 \\
-1.03 \pm 0.40 \\
0.00 \pm 0.29\end{array}$ & $\begin{array}{l}*-1 \cdot 20 \pm 0 \cdot 34 \\
+0 \cdot 17 \pm 0 \cdot 36 \\
-\end{array}$ & $\begin{array}{l}- \\
-1 \cdot 26 \pm 0.28 \\
-0.21 \pm 0.27\end{array}$ \\
\hline
\end{tabular}

Mean \pm SEM; ${ }^{*} \mathbf{P}<0.05$.

Advancement in bone age which is not associated with equal improvement in height may therefore be an ultimate disadvantage.

In addition to growth studies, we also noted the effects of the diet on lung function and chest $x$-rays, and this will be reported elsewhere. No significant beneficial effects were observed.

Our experience with this diet leads us to conclude that it may have a limited place, as short-term treatment, for patients who are failing to thrive. These are likely to be in the younger age group, where the best responses were seen. It might, for example, be used in children recovering from a surgical operation. We have no evidence that its long-term use is likely to be beneficial to many patients, and we feel that the restriction of normal life which is implicit in this unpleasant and highly artificial mode of nutrition outweighs the small improvements in growth that we observed. We would therefore not recommend it as routine treatment for CF.

This study was supported by a grant from the Cystic Fibrosis Research Trust.

We are grateful to Dr M. Preece, Department of Growth and Development, Institute of Child Health, for help and advice on growth data; to Mrs L. Mercy, for measuring the children throughout the study; to paediatricians in South Wales, who kindly allowed us to study their patients; to the nursing staff in the paediatric units and to the Department of Medical Illustration in the University Hospital of Wales and the Tenovus Institute of Cancer Research; and, lastly, to the patients and their parents, without whose co-operation this study would not have been possible.

\section{References}

Allan, J. D., Mason, A., and Moss, A. D. (1973). Nutritional supplementation in treatment of cystic fibrosis of the pancreas. American Journal of Diseases of Children, 126, 22-26.

Berry, H. K., Kellogg, F. W., Hunt, M. M., Ingberg, R. L., Richter, L., and Gutjahr, C. (1975). Dietary supplement and nutrition in children with cystic fibrosis. American Journal of Diseases of Children, 129, 165-171.

Clarke, C. G., and Hadfield, G. (1924). Congenital pancreatic disease with infantilism. Quarterly Journal of Medicine, 17, 358-364.

Doershuk, C. F., Matthews, L. W., Tucker, A. S., Nadelman, H., Eddy, G., Wise, M., and Spector, S. (1964). A 5-year clinical evaluation of a therapeutic program for patients with cystic fibrosis. Journal of Pediatrics, 65, 677-693.

Harper, M. H. (1930). Two cases of congenital pancreatic steatorrhoea with infantilism. Medical Journal of Australia, 2, 663-664.

Lober, C. W. (1975). Letter: Nutritional supplementation in cystic fibrosis. American Journal of Diseases of Children, $129,1239$.

Passini, F. (1919). Disease of the pancreas as a cause of failure to thrive in children. Deutsche medizinische Wochenschrift, 45, 851-853. 
Robinson, M. J., and Norman, A. P. (1975). Life tables for cystic fibrosis. Archives of Disease in Childhood, 50, 962-965.

Shwachman, H., and Kulczycki, L. L. (1958). Long-term study of one hundred and five patients with cystic fibrosis. American Journal of Diseases of Children, 96, 6-15.

Sproul, A., and Huang, N. (1964). Growth patterns in children with cystic fibrosis. Journal of Pediatrics, 65, 664-676.

Tanner, J. M. (1973). Physical growth and development. In Textbooi: of Paediatrics, p. 270 . Edited by J. O. Forfar and G. C. Arneil. Churchill Livingstone: Edinburgh.

Tanner, J. M., and Whitehouse, R. H. (1975). Revised standards for triceps and subscapular skinfolds in British children. Archives of Disease in Childhood, 50, 142-145.
Tanner, J. M., Whitehouse, R. H., Marshall, W. A., Healy, M. J. R., and Goldstein, H. (1975). Assessment of Skeletal Maturity and Prediction of Adult Height (TW2 Method). Academic Press: London.

Tanner, J. M., Whitehouse, R. H., and Takaishi, M. (1966). Standards from birth to maturity for height, weight, height velocity, and weight velocity: British children, 1965. Archives of Disease in Childhood, 41, 454-471, 613-635.

Correspondence to Dr J. A. Dodge, Department of Child Health, Welsh National School of Medicine, Heath Park, Cardiff CF4 4XN.

\section{Erratum}

Table 1 p. 590 (July issue) in the Short Report 'Repeat lumbar puncture in the diagnosis of meningitis' should be as follows:

Table 1 Cerebrospinal fuid findings in the case described

\begin{tabular}{|c|c|c|c|}
\hline $\begin{array}{l}\text { Time after onset } \\
\text { of illness }(h)\end{array}$ & $\begin{array}{l}\text { Time after } \\
\text { admission }(h)\end{array}$ & $\begin{array}{l}W B C \\
\left(\times 10^{6} / l\right)\end{array}$ & $\begin{array}{l}R B C \\
\left(\times 10^{6} / l\right)\end{array}$ \\
\hline $\begin{array}{l}14 \\
27\end{array}$ & $\begin{array}{l}1 \\
13 \\
\text { (Subdural fluid) }\end{array}$ & 1 & $\begin{array}{l}240 \\
\text { Masses }\end{array}$ \\
\hline $\begin{array}{l}28 \\
70 \\
94\end{array}$ & $\begin{array}{l}14 \\
56 \\
80\end{array}$ & $\begin{array}{r}4800 \\
25000 \\
154\end{array}$ & $\begin{array}{r}1800 \\
0 \\
4\end{array}$ \\
\hline
\end{tabular}

